УДК 37.02

DOI $10.21661 / \mathrm{r}-466525$

\title{
Н.Ю. Милютинская
}

\section{СПЕЦИФИКА ФОРМИРОВАНИЯ МЕЖКУЛЬТУРНОЙ КОММУНИКАТИВНОЙ КОМПЕТЕНЦИИ В ПРОФЕССИОНАЛЬНОЙ ПОДГОТОВКЕ БАКАЛАВРОВ ФИЛОЛОГИИ}

Аннотация: в статье рассматриваются основные понятия, связанные с межкультурным общением в контексте современного иноязычного образования, анализируются основные проблемы обучения межкультурному общению, заключающчиеся в выборе ведущуего подхода обучения, постановке чүели и отборе культурно-языковых учебных заданий. Эфффективности формирования межкультурной коммуникативной компетенцуии способствует алгоритм действий по введению и закреплению учебного культурно-окраченного материала, который включает этапь культуроведческой ориентации, рецеепции, осмьсления, эвалюацчии и рефлексии.

Ключевые слова: межкультурное общеение, межкультурная коммуникативная компетенция, медиатор культур, компетентностный подход, система культурно-языковых учебных заданий.

\section{N. Yu. Milyutinskaya}

\section{SPECIFIC FEATURES OF INTERCULTURAL COMMUNICATIVE COMPETENCE DEVELOPMENT IN PHILOLOGICAL VOCATIONAL TRAINING}

Abstract: the paper outlines the main concepts of intercultural communication in modern foreign language educational environment. It touches upon the major problems of teaching intercultural communication regarding culture and language teaching approaches, goal setting, culture and language based activities. The action plan of teaching culture and language consists of several stages: cultural concept orientation, reception, cognition, evaluation and reflection and is introduced as an effective tool for intercultural competence development. 
Keywords: intercultural communication, intercultural communicative competence, culture mediator, competency-based approach, system of learning activities for culture and language.

Современное состояние проблем, связанных с межкультурным общением, характеризуется высокой степенью исследовательского интереса и как следствие глубокой и всесторонней теоретической разработанностью. Понятие межкультурное общение дополнено данными из области таких наук как философия, культурология, психология, психолингвистика, межкультурная коммуникация и концептология, лингвистика, социолингвистика, этнолингвистика и педагогика. Анализ научной литературы по данной проблеме позволяет судить, что учёными изучены следующие вопросы: характеристики культуры и её функций (Ю.М. Лотман, М. С. Каган); социального становления и приобщения индивидуума к культуре (М.М. Бахтин, В.С. Библер, М.К. Мамардашвили,); взаимоотношения человека, культуры и образования (Е.В. Бондаревская, И.Ф. Исаев, В.А. Сластёнин); аспекты соизучения языка и культуры (С.Г. Тер-Минасова, Ю.Н. Верещагин, В.Г. Костомаров, Г.В. Елизарова, Т. В. Ларина); психологические черты и качества личности и особенности коммуникативного поведения (М. Байрам, М. Беннет, И.А. Стернин, Л.П. Крысин, В.Н. Куницына); вопросы психологии общения, процессы восприятия речи (А.А. Леонтьев, В.А. Артёмов, И.А. Зимняя, И.Н. Горелов); проблемы взаимоотношения языка и личности, концептология (В.И. Карасик, Ю.С. Степанов, И.А. Стернин); модели обучения межкультурному общению и формирование языковой личности (В.В. Сафонова, Н.Д. Гальскова, Н.В.Барышников Г.В. Елизарова, Е.Г. Тарева). Исследования учёных по обозначенной выше проблематике свидетельствуют о солидном накопленном теоретическом опыте, который служит базисом для построения содержания обучения межкультурному общению (далее МО) на всех образовательных ступенях: дошкольного, начального, среднего и высшего иноязычного образования. Однако поиск путей эффективного обучения МО остаётся актуальным и на сегодняшний день. Вопросы, связанные с данной проблемой, актуализированы двумя причинами: с одной стороны, социальным заказом и изменившимися 
целевыми ориентирами иноязычного образования, отраженными в Федеральном Государственном Образовательном Стандарте по высшему образованию, с другой стороны, недостаточной технологической обеспеченностью процесса обучения МО, а также профессиональной неготовностью преподавателей внедрять технологии обучение языку и культуре на качественно новой основе. Основная цель современного иноязычного образования заключается в формировании нового типа личности, способной осуществлять общение на основе принципов толерантности, сотрудничества и понимания социальных, культурных и личностных различий для решения коммуникативных задач в профессиональной, социальной и межкультурной сферах деятельности. В связи с целевой установкой формирование межкультурной коммуникативной компетенции (далее МКК) приобретает приоритетное значение. Однако в практике соизучения языка и культуры в основном преобладают классический лингвистический и лингвострановедческий подходы, которые не в полной мере удовлетворяют сложившейся парадигме обучения МО. Во-первых, с позиций этих подходов не учитывается фактор равноправия между иноязычной и родной культурами, в этом случае иноязычная культура оказывается культурно доминирующей. Во-вторых, формирование языковой парасреды осложняет отсутствие дидактического оснащения, включающего систему «текстов культуры» (художественные, публицистические, научные; фотографии, картины и т. д.), аудиовизуальные материалы, культурноязыковые учебные задания, средства диагностики и контроля сформированности МКК. Следовательно, возникает необходимость уточнения цели обучения ИМО и способов формирования МКК. Содержание МКК отражает положения лингвистической, социолингвистической, дискурсивной, стратегической, социокультурной и социальной субкомпетенций, однако не следует забывать о том, что МКК - это «компетенция особой природы». «Целью формирования МКК является достижение такого качества языковой личности, которое позволит ей выйти за пределы собственной культуры и приобрести качества медиатора культур, не утрачивая собственной культурной идентичности» [3, с. 236]. Осуществление данной цели обеспечивается положениями ряда подходов. Учитывая, 
отмеченную учёными тенденцию, корреляции отдельных аспектов разных подходов [1, с. 334; 7, с. 26] нам представляется целесообразным ориентироваться на компетентностный подход, в качестве доминирующего, который представляет собой формирование суммы ключевых компетенций и личных качеств обучающихся как интегративной результативно-целевой основы в процессе обучения МО. Однако, стоит отметить, что в содержании компетентностного подхода оказываются включёнными некоторые положения личностно-деятельностного, межкультурного, коммуникативно-когнитивного подходов. Так, например, в русле компетентностного подхода, как доминанты обучения МО представлен личностный аспект (мотивация, ценностные ориентации, личностные качества); деятельностный аспект (эффективная и продуктивная деятельность, опыт деятельности); когнитивный аспект (знания, умения, способность к самопознанию и самообучению); межкультурный аспект (общечеловеческие культурные и духовные ценности, способность к адекватному взаимодействию, социокультурные знания и умения) $[7$, с. 25].

Дидактическое оснащение процесса овладения МКК включает современные принципы; алгоритмизированный способ введения и закрепления материала; культурно-окрашенные учебные аудио-материалы, система «текстов культуры» (публицистические; фотографии и тд.); тематика культурно-обусловленных ситуаций повседневного общения, а также система культурно-языковых учебных заданий и средств учебной диагностики. Анализ научной литературы по специфике формирования МКК [3, с. 237; 4 с. 5] позволяет включить в учебнометодическое сопровождение следующие принципы: 1) принцип познания и учёта культурных универсалий, представляющий основу для сопоставления культур применительно к таким глобальным понятиям, которые вмещают проявления какого-либо качества и позволяют с момента знакомства с категориями культуры избежать экстраполяции собственных культурных представлений на культуру иноязычную; 2) принцип культурно-связанного соизучения иностранного и родного языков предполагает объяснение неразрывной связи каждого конкретного языка с соответствующей культурой и 
понимание природы языка как носителя культуры (соотнесение языковых средств выражения с соответствующим им культурным ценностям); 3) принцип речеповеденческих стратегий позволяет выработать у обучаемого основную линию поведения, базирующейся на знании о культурных универсалиях, о собственных культурных ценностях и способах их отражения в поведении, на знаниях, касающихся культуры изучаемого языка, на знаниях о возможном конфликте или взаимодействии культур, на знаниях о способах медиации во время такого взаимодействия; 4) принцип эмпатии направлен на формирование такого качества характера языковой личности, как способность сопереживания другому индивиду, принадлежащего другой культуре; 5) принцип дидактической культуросообразности, определяющий отбор культуроведческого материала, отличающегося, прежде всего, аутентичностью и обеспечивающий цельность представления о моделях человеческого бытия в разных культурах.

Анализ научной литературы по проблемам овладения МКК [2, с. 16] позволил определить алгоритм действий, состоящий из следующих этапов: 1) культуроведческой ориентации (выдвижение гипотез о сущности предложенного культурного концепта, речевая интеллектуальная разминка); 2) рецепции (соотнесение содержания текста аудиозаписи с определением обсуждаемого концепта); 3) осмысление (сопоставление ценностей чужой и родной культуры); 4) эвалюации (оценочное суждение, выражение личного отношения к проблеме); 5) рефлексии (оценивание собственной деятельности в качестве медиатора культур).

Каждому этапу соответствует определённая система культурно-языковых учебных заданий:

Этап культуроведческой ориентащчии представлен заданиями:

- «мозговой штурм», в ходе которого студенты совместными усилиями или индивидуально разрабатывают семантическое поле какого-либо культурного понятия (концепта) на определённую тему;

- языковая и контекстуальная догадка.

Этап рец̧епu̧ии представлен заданиями: 
- соотнесение содержания текста с невербальными элементами, например, картинкой, фотографией, схемой;

- культурно-содержательный и смысловой выбор ответов и суждений по теме («верные / неверные утверждения»);

- соотнесение специфических языковых явлений (уровень лексики, грамматики) и культурных универсалий, способствующих развитию механизмов аудитивного восприятия и мыслительного процесса: узнавания, осмысления, содержательной антиципации.

Этап осмысления представлен заданиями:

- сопоставление ценностей чужой и родной культуры за счёт детализации, уточнения, описания культурно-окрашенного материала;

- обмен информацией по типу «мозаики». Студентам предлагается часть информации, содержащей культурные особенности страны изучаемого языка, после ознакомления со своей «порцией» информации, обучающиеся обмениваются информацией и восстанавливают общее содержание текста;

- логическая группировка, предполагающая выстраивание информации социокультурного характера согласно плану или критериям;

- ситуативные диалоги, целью которых является моделирование собственной роли медиатора, действующего на стыке двух культур;

- творческая презентация.

Этап эвалюации включает задания:

- проблемно-поисковые;

- проведение интервью по теме;

- дискуссия (форма направляемой дискуссии (на основе текста предлагаются вербальные опоры, например, направляющие вопросы, таблицы, схемы), свободной дискуссии, диспута, построенного заранее на выступлениях студентов, представляющих противоположную точку зрения);

- создание презентаций, демонстрирующих личное отношение к проблеме;

- участие в ролевых играх; 
- устное выступление по определенной теме, которое характеризуется наличием проблемной ситуации, на решение которой направлено выступление, углублённостью содержания, чёткой структурой, сложностью и разнообразием языковой формы;

- проектная деятельность, которая предполагает самостоятельное групповое планирование и творческую реализацию темы проекта.

Этап рефлексии представлен опросниками и обучающими диагностическими анкетами.

Особое внимание уделяется выбору средств обучения, к которым относятся: культурно-окрашенные функциональные материаль (аудиозаписи образцов речевых актов диалогического и монологического характера представителей иноязычной культуры; тексты); содержательные вербальныле опоры (планы, вопросы, списки слов и словосочетаний, каркасы диалогического общения, «тексты культуры» (публицистические)); содержательные невербальные опоры «тексты культуры» (фотографии, рисунки) для моделирования «культурного пространства» на занятии [5, с. 8].

В заключение отметим, что эффективность овладения МКК зависит от чёткого понимания цели обучения МО, определения концептуальной базы и построения содержания обучения МО, включающего: систему современных принципов и способов введения и закрепления учебного культурно-окрашенного материала, а также систему «текстов культуры» и культурно-обусловленных ситуаций, культурно-языковые учебные задания и средства учебной диагностики. Думается, что вопрос проектирования и апробации технологий овладения МКК требует большего времени, конкретизации и открытых дискуссий.

\section{Сиисок литературы}

1. Гальскова Н.Д. Теория обучения иностранным языкам. Лингводидактика и методика: Учебное пособие для студентов лингвистических университетов и факультетов иностранных языков высших педагогических учебных заведений. М.: Академия, $2009-334$ с. 
2. Голубкова О.Н. Культуроведчески-ориентированная интерпретация иноязычных художественных текстов в профессиональном языковом образовании: Автореф. дис. ... канд. пед. наук. - Екатеринбург, 2003. - 22 с.

3. Елизарова Г. В. Культура и обучение иностранным языкам. - СПб.: Каро, 2005. $-351 \mathrm{c}$.

4. Колкова М.К. Культуроведческий подход к обучению межкультурному иноязычному общению и его основные принципы // Современная методика соизучения иностранных языков и культур. - СПб.: Каро, 2011. - С. 4-8.

5. Милютинская Н.Ю. English through cultural understanding: Учебное пособие. Н.Ю. Милютинская, С. Форд. - Ижевск: Удмуртский университет, 2010. 107 c.

6. Тарева Е.Г. Межкультурная коммуникативная компетенция // Профессиональное становление учителя иностранного языка в системе педагогического образования: Материалы Международной конференции, - М.: МГПУ; Языки Народов Мира; Тезаурус, 2017 - С. 31-38.

7. Щепилова А.В. Методика обучения иностранным языкам на современном этапе: полиподходность или полипарадигмальность // Профессиональное становление учителя иностранного языка в системе педагогического образования: Материалы Международной конференции. - М.: МГПУ; Языки Народов Мира; Teзаурус, 2017 - C. 24-30.

\section{References}

1. Gal'skova, N. D. (2009). Teoriia obucheniia inostrannym iazykam. Lingvodidaktika i metodika: Uchebnoe posobie dlia studentov lingvisticheskikh universitetov i fakul'tetov inostrannykh iazykov vysshikh pedagogicheskikh uchebnykh zavedenii. M.: Akademiia p.334

2. Golubkova, O. N. (2003). Kul'turovedcheski-orientirovannaia interpretatsiia inoiazychnykh khudozhestvennykh tekstov $\mathrm{V}$ professional'nom iazykovom obrazovanii: Avtoref. dis. Ekaterinburg p. 22

3. Elizarova, G. V. (2005). Kul'tura i obuchenie inostrannym iazykam. SPb.: Karo. p. 351 
4. Kolkova, M. K. (2011). Kul'turovedcheskii podkhod $\mathrm{k}$ obucheniiu mezhkul'turnomu inoiazychnomu obshcheniiu i ego osnovnye printsipy. Sovremennaia metodika soizucheniia inostrannykh iazykov i kul'tur, pp. 4-8. SPb.: Karo

5. Miliutinskaia, N. Iu., \& Ford, S. (2010). English through cultural understanding: Uchebnoe posobie. N.Iu. Miliutinskaia, p. 107 Izhevsk: Udmurtskii universitet

6. Tareva, E. G. (2017). Mezhkul'turnaia kommunikativnaia kompetentsiia. Professional'noe stanovlenie uchitelia inostrannogo iazyka $\mathrm{v}$ sisteme pedagogicheskogo obrazovaniia, pp. 31-38. M.: MGPU

7. Shchepilova, A. V. (2017). Metodika obucheniia inostrannym iazykam na sovremennom etape: polipodkhodnost' ili poliparadigmal'nost'. Professional'noe stanovlenie uchitelia inostrannogo iazyka v sisteme pedagogicheskogo obrazovaniia, pp. 24-30. M.: MGPU

Милютинская Наталия Юрьевна - канд. пед. наук, доцент кафедры романской филологии второго иностранного языка и лингводидактики ФГБОУ ВО «Удмуртский государственный университет», Россия, Ижевск.

Milyutinskaya Nataliya Yurievna - candidate of pedagogical sciences, associate professor of the Department of Roman Philology Second Foreign Language and Language Pedagogy at Udmurt State University, Russia, Izhevsk 